\title{
Is Pregnancy a Risk Factor for Future Cardiovascular Events?
}

\author{
Shibba Takkar Chhabra ${ }^{1} \quad$ Ruhani Bali $^{2} \quad$ Tripat Kaur $^{1} \quad$ Bhupinder Singh ${ }^{1} \quad$ Abhishek Goyal $^{1}$ \\ Rohit Tandon ${ }^{2}$ Naved Aslam ${ }^{1}$ Bishav Mohan ${ }^{1} \quad$ Gurpreet Singh Wander ${ }^{1}$ \\ 1 Department of Cardiology, Hero DMC Heart Institute, Dayanand \\ Medical College and Hospital Unit, Ludhiana, Punjab, India \\ 2 Department of Medicine, Hero DMC Heart Institute, Dayanand \\ Medical College and Hospital Unit, Ludhiana, Punjab, India

\begin{abstract}
Address for correspondence Shibba Takkar Chhabra, DM, Department of Cardiology, Hero DMC Heart Institute, Dayanand Medical College and Hospital Unit, Ludhiana 141001, Punjab, India (e-mail: shibbachhabra@yahoo.com).
\end{abstract}

Indian J Cardiovasc Dis Women-WINCARS 2017;2:56-62.

\author{
Abstract \\ Keywords \\ - assisted reproductive \\ technology \\ - cardiovascular \\ disease \\ - gestational diabetes \\ mellitus \\ - hypertensive \\ disorders of \\ pregnancy \\ - maternal placental \\ syndromes \\ - pregnancy \\ - supraventricular \\ tachycardia
}

Pregnancy is a normal physiologic state in a woman's life, and according to traditional beliefs, it may not be predictive of future cardiovascular disease (CVD) lest it is complicated by some adverse events. Contrary to the previous beliefs, the complications are not limited to pregnancy period and may leave permanent vascular and metabolic damage. Factors such as lipid inflammatory pathways and vascular functions play a vital role in determining the cardiovascular risk in pregnancy. In addition to modifiable and nonmodifiable risk factors, emerging factors like genetics and epigenetics risk, obesity, metabolic syndrome, lifestyle, inflammatory and hypertensive disorders, and endothelial dysfunction with gestational diabetes help in determining the future CVD.

The present debate is an effort to study that besides the common risk factors such as gestational hypertension, gestational diabetes, and preeclampsia, preterm delivery, assisted reproductive technology-related pregnancy events, and arrhythmias also have a bearing on future cardiovascular risk of a woman. The awareness in the medical community especially obstetricians, physicians, and cardiologists may play a pivotal role in detecting these complications and appropriate follow-up.

\section{Is Normal Pregnancy a Predictor of Future Cardiovascular Disease?}

\section{No-It Is Not a Predictor}

Pregnancy with normal course is probably not a predictor of future cardiovascular disease (CVD). Pregnancy-induced changes in cardiovascular system (CVS) develop primarily to meet the increase metabolic demands of the mother and fetus. Despite the increased workload of the heart during gestation and labor, the healthy woman has no impairment of cardiac reserve.

Epidemiologic studies show that the risk of coronary artery disease is much lower in premenopausal women compared with age matched men, but the risk differential disappears in postmenopausal females. A body of research suggests that hormonal differences between pre- and postmenopause contribute to the cardioprotection for premenopausal women. The reproductive hormones primarily estrogen modulates cardiovascular function through several mechanisms such as stress-induced activation of hypothalamic pituitary-axis and sympathetic adrenomedullary system. Also, lactation is associated with a lower prevalence of hypertension, diabetes, hyperlipidemia, and CVD.

Hence, pregnancy is a normal physiologic state in a women's life and may not be predictive of future CVD lest it is complicated by some adverse events.

\section{Yes-It Is a Predictor}

Since times immemorial, there had been a gender bias as regards to risk prediction tools. Pregnancy is a special part of women's life and pregnancy-related complications can be a 
Table 1 Hemodynamic changes in pregnancy

\begin{tabular}{|l|l|l|}
\hline \multicolumn{3}{|l|}{ Pregnancy and heart hemodynamics during pregnancy } \\
\cline { 1 - 2 } $\begin{array}{l}\text { Peripheral resistance } \downarrow \\
\uparrow \text { uterine blood flow }\end{array}$ & $\begin{array}{l}\text { Cardiac } \\
\text { output } \uparrow 30 \%\end{array}$ \\
\cline { 1 - 2 } Blood volume & $\uparrow 40-45 \%$ & \\
\hline Heart rate & $\uparrow 10-20 \%$ & \\
\hline Blood pressure & Or $\downarrow$ & \\
\cline { 1 - 2 } $\begin{array}{l}\text { Pulmonary vascular } \\
\text { resistance }\end{array}$ & $\downarrow$ & \\
\hline $\begin{array}{l}\text { Venous pressure in } \\
\text { lower extremities }\end{array}$ & $\uparrow$ & \\
\hline
\end{tabular}

signal toward forthcoming CVD in future years. Present CVD risk prediction tools underestimate short term in risk women and more so in pregnant women. Pregnancy experienced by $85 \%$ of women has been likened to a cardiac stress test and provides important clues about a woman's underlying predisposition for both near- and far-term CVD events (- Table 1).

It is important to understand that even in normal patients, pregnancy imposes some dramatic physiologic changes upon the CVS. Major hemodynamic changes occur during pregnancy, labor and delivery, and the postpartum period ( - Table 1). These changes begin in the first 5 to 8 weeks of gestation and peak late in the second trimester. Blood volume increases 40 to $50 \%$ during normal pregnancy and outweighs the increase in red blood cell mass, contributing to the fall in hemoglobin concentration, otherwise known as anemia of pregnancy. Similarly, cardiac output rises 30 to $50 \%$ above baseline, peaks at the end of the second trimester, and reaches a plateau until delivery. The increase in cardiac output is achieved by three factors: an increase in preload due to greater blood volume, reduced after load due to a fall in systemic vascular resistance (SVR), and a rise in the maternal heart rate by 10 to 15 beats $/ \mathrm{min}$. Stroke volume increases during the first and second trimesters but declines in the third trimester due to compression of the inferior vena cava by the uterus, at which point heart rate is the major factor in the increase in cardiac output. Blood pressure typically falls approximately $10 \mathrm{~mm}$ $\mathrm{Hg}$ below baseline by the end of the second trimester due to reduction in SVR and addition of new blood vessels in the uterus and placenta. ${ }^{1}$

Pregnancy stresses on maternal carbohydrate, lipid inflammatory pathways, and vascular functions. Hence, pregnancyrelated adverse events are female-specific CVD risk factor. These adverse events include pregnancy-related hypertension, gestational hypertension, preeclampsia, eclampsia, gestational diabetes mellitus (GDM), and preterm delivery ( - Table 2 ).

With increasing maternal age, prepregnancy risk factors now play an important role in determining the pregnancyrelated complications and postpregnancy CVD outcomes (-Fig. 1).

Underlying prepregnancy risk factors such as race, maternal age, parity, hypertension, obesity, smoking, dyslipidemia, and genetic or acquired CVD predisposition determine the outcome of pregnancy. Presence of genetic predisposition could activate inflammatory pathways, lead to endothelial dysfunction and oxidative stress, and hamper normal maternal fetal interplay predisposing to development of pregnancy and CVD complications. These could further be harbinger of future CVD. The present debate discusses the pregnancy-related issues under the following headings:

Table 2 Female sex and CVD risk factors and conditions

\begin{tabular}{|c|c|c|c|}
\hline Female-specific CVD risk factor & $\begin{array}{l}\text { Female-predominant } \\
\text { CVD risk factor }\end{array}$ & $\begin{array}{l}\text { Female-specific } \\
\text { CVD conditions }\end{array}$ & $\begin{array}{l}\text { Female-predominant } \\
\text { CVD conditions }\end{array}$ \\
\hline $\begin{array}{l}\text { Adverse pregnancy outcomes } \\
\text { Pregnancy-related hypertension: } \\
\text { Gestational hypertension } \\
\text { Pre-eclampsia } \\
\text { Eclampsia } \\
\text { Gestational diabetes mellitus } \\
\text { Preterm delivery }\end{array}$ & $\begin{array}{l}\text { Autoimmune inflammatory } \\
\text { diseases: } \\
\text { Rheumatoid arthritis } \\
\text { Systemic lupus } \\
\text { erythematosus } \\
\text { Scleroderma }\end{array}$ & $\begin{array}{l}\text { Peripartum } \\
\text { cardiomyopathy }\end{array}$ & $\begin{array}{l}\text { Myocardial infarction with } \\
\text { nonobstructive coronary arteries }\end{array}$ \\
\hline Polycystic ovarian syndrome & Breast cancer & & $\begin{array}{l}\text { Takotsubo cardiomyopathy/ } \\
\text { apical ballooning syndrome/ } \\
\text { stress-induced cardiomyopathy } \\
\text { Nonobstructive ischemic heart } \\
\text { disease } \\
\text { Coronary microvascular dysfunction } \\
\text { Endothelial dysfunction }\end{array}$ \\
\hline $\begin{array}{l}\text { Functional hypothalamic } \\
\text { amenorrhea }\end{array}$ & & & $\begin{array}{l}\text { Heart failure with preserved } \\
\text { ejection fraction }\end{array}$ \\
\hline Reproductive hormones & & & $\begin{array}{l}\text { Spontaneous coronary artery dissection } \\
\text { Postural orthostatic tachycardia } \\
\text { syndrome } \\
\text { Coronary vasospasm } \\
\text { Pulmonary hypertension }\end{array}$ \\
\hline
\end{tabular}

Abbreviation: CVD, cardiovascular disease.

Adapted from: Gulati M. Improving the cardiovascular health of women in the nation. Circulation 2017;135:495-498. 


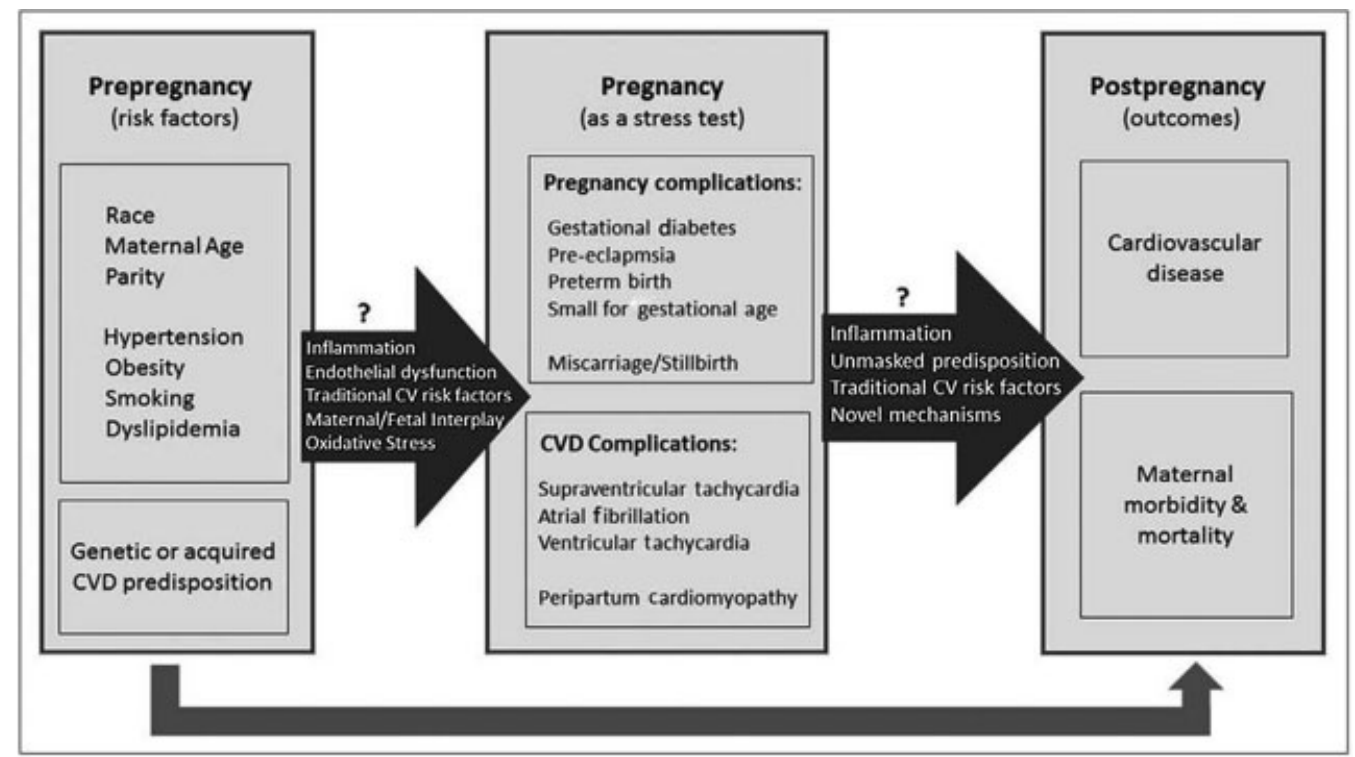

Fig. 1 Pregnancy-related complications and CVD events: the association between prepregnancy risk factors and postpregnancy outcomes. CVD, cardiovascular disease.

- Pregnancy complications: Gestational diabetes, preeclampsia, preterm birth, small for gestational age, and miscarriage/stillbirth.

- CVD complications: Supraventricular tachycardia (SVT), atrial fibrillation, ventricular tachycardia, and peripartum cardiomyopathy.

\section{Hypertensive Disorders of Pregnancy}

Hypertensive disorders of pregnancy (HDP) are one of the most common complications of pregnancy (6-8\%). HDP include chronic hypertension, gestational hypertension, and pre-eclampsia de novo or superimposed.

Pre-eclampsia is diagnosed as a blood pressure $(B P)>140 /$ $90 \mathrm{~mm} \mathrm{Hg}$, with a proteinuria of $0.3 \mathrm{~g} / 24 \mathrm{~h}$ after 20 weeks of gestation. ${ }^{2}$ Early pre-eclampsia and severe pre-eclampsia increase the risk of CVDs. In an epidemiologic study by Bellamy et $\mathrm{al}^{3}$ the data from 2 million women (13-15 years follow-up) showed that fatal myocardial ischemic events increased by 2.6 times, regardless of severity of pre-eclampsia. In females with pre-eclampsia and preterm delivery, a mortality increase by 8 times was seen. ${ }^{4-7}$ The meta-analyses also showed an increase in relative risk (RR) of hypertension by 3.70 , ischemic heart disease (IHD) by 2.16 , stroke by 1.81 , and venous thromboembolism (VTE) by 1.79 . Moreover, in a review by Lykke et $\mathrm{al}^{8}{ }^{8}$ pre-eclampsia was associated with a threefold increase in risk for chronic hypertension. Also, in the study, in comparison to normotensive women, these women had double the risk for cardiovascular mortality.

Moreover, HDPs are strongly associated with subsequent type 2 diabetes mellitus and hypertension. The severity, parity, and recurrence of hypertensive pregnancy disorders increase the risk of subsequent cardiovascular events. The subsequent risk of diabetes increased by 3.12 times in gestational hypertension and by 3.68 times in severe pre-eclampsia.

\section{Gestational Diabetes and Future CVD}

Gestational diabetes mellitus (GDM) affects many women in pregnancy and is enhanced by epidemic conditions of obesity, increasing age at the time of the first pregnancy, stressful life conditions, a sedentary lifestyle with less physical activity, and unhealthy nutrition with highly processed, high-calorie food intake. GDM does not affect the mother and offspring in pregnancy alone, as there is compelling evidence of the long-term effects of the hyperglycemic state in pregnancy postpartum. Increased glucose levels and diabetes mellitus are well-known cardiovascular risk factors, in addition to other modifiable and unmodifiable risk factors that are relevant for metabolic diseases and CVDs. There is an interplay of factors such as genetic and epigenetic risk, dyslipidemia, obesity, metabolic syndrome, lifestyle, inflammatory, hypertensive disorders, and endothelial dysfunction with gestational diabetes in determining future CVD (-Fig. 2).

Several novel markers have been identified to determine the pathophysiology of GDM. These include markers of endothelial dysfunction such as apelin that is a recently discovered adipocytokine (suppressed in GDM). Another marker osteoprotegerin (OPG), a soluble member of the tumor necrosis factor (TNF) receptor super family, has higher levels in GDM. Pentraxin 3 (PTX3) has cardioprotective role and is decreased in GDM. These could be potential therapeutic targets in preventing future CVD. ${ }^{9}$

Even in the absence of gestational diabetes, women who receive an oral glucose tolerance test in pregnancy (typically after abnormal results of a glucose challenge test) may have an increased incidence of subsequent CVD. The presence of both high maternal weight and GDM compounds the risk of developing diabetes. However, the association between overweight alone and GDM alone and hypertension and CVD appears similar, suggesting a need for effective interventions 


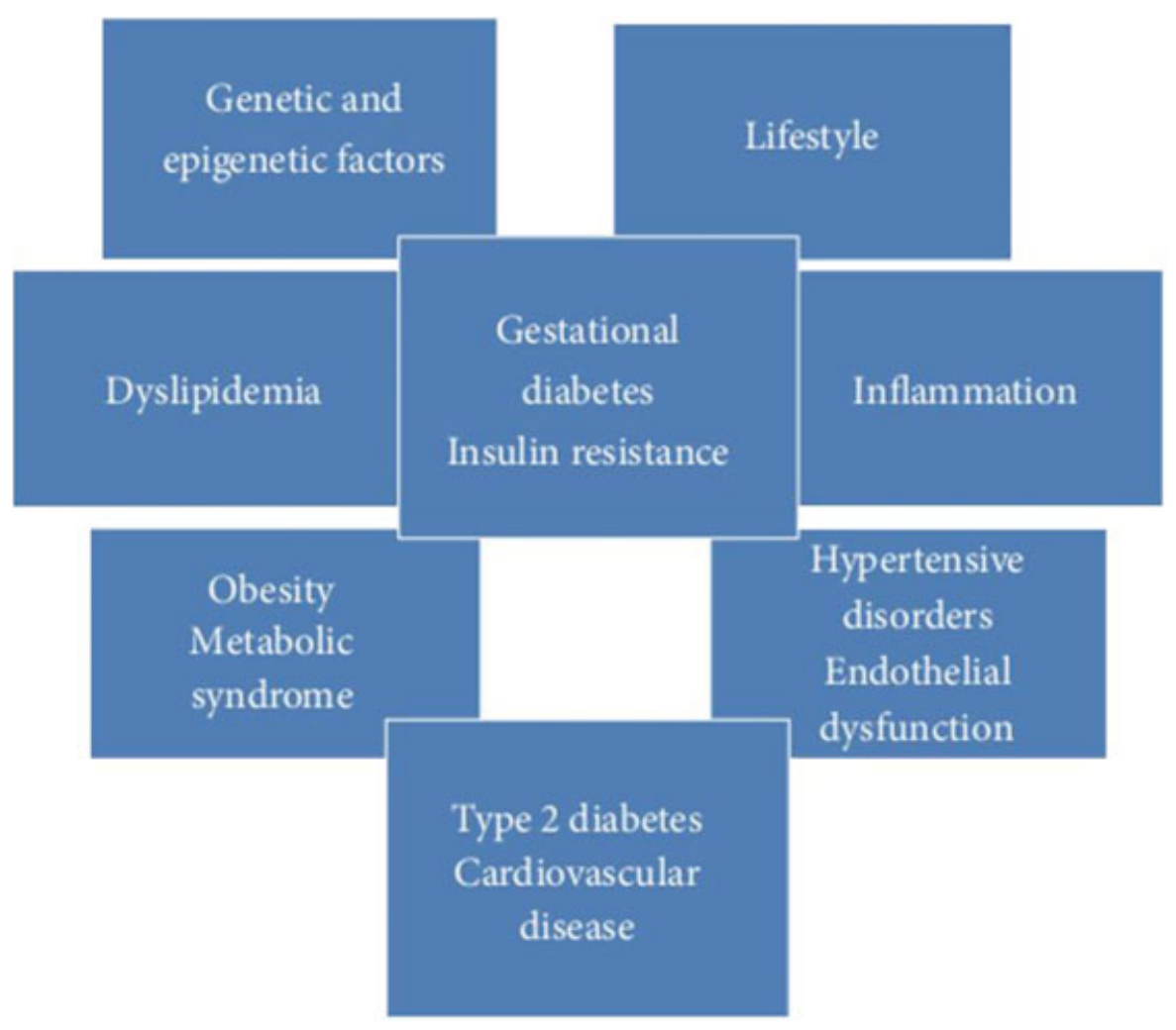

Fig. 2 Multifactorial association of gestational diabetes mellitus with cardiovascular disease. (Adapted from: Burlina et al. ${ }^{9}$ )

to manage both these conditions to improve the health of these patients. ${ }^{10}$

Another noteworthy fact is that among women with a family history of type 2 diabetes, those with prior GDM were even more likely to not only have CVD risk factors, including metabolic syndrome and type 2 diabetes but also to have experienced CVD events, which occurred at a younger age. Thus, women with both a family history of type 2 diabetes and personal history of GDM may be especially suitable for early interventions aimed at preventing or reducing their risk of CVD and diabetes.

\section{Metabolic Syndrome and Maternal Placental Syndrome and Cardiovascular Risk}

Maternal placental syndromes (MPS), including the HDP and abruption or infarction of the placenta, likely originate from diseased placental vessels. MPS is more common in women who exhibit the metabolic syndrome and classic risk factors for CVD, including obesity, prepregnancy hypertension, diabetes mellitus, and dyslipidemia. The link between the MPS and premature CVD is likely mediated by a woman's metabolic syndrome profile, thus providing an early opportunity for the prevention of CVD in women through dietary and lifestyle modifications.

Individual maternal features of the metabolic syndrome, such as obesity, ${ }^{11}$ insulin resistance, ${ }^{12}$ dyslipidemia, ${ }^{13}$ and chronic hypertension, ${ }^{14}$ are likely risk factors for MPS. Literature suggests that women with the metabolic syndrome prior to delivery are at higher risk of MPS. ${ }^{13}$ Several cohort studies of the future risk of CVD following MPS, low infant birth weight, and/or preterm delivery have found an increased RR of future IHD and cardiovascular death (-Table 3 ).

Moreover, in an interesting review, Ray et $\mathrm{al}^{15}$ reported an increased risk of premature CVD in association with MPS, especially when it was associated with impaired fetal growth or fetal death (-Fig. $\mathbf{3}$ ).

\section{Arrhythmia in Pregnancy}

Paucity exists regarding the trends of frequency and outcome of arrhythmias in pregnancy. In women of reproductive age, the most common arrhythmia is paroxysmal supraventricular tachycardia (PSVT). Atrioventricular nodal re-entry and Wolf-Parkinson-White syndrome account for the majority of SVT in this population, with an incidence of 1.2 per 1,000 people. Over half these patients are symptomatic. Pregnancy has been identified as a risk factor for paroxysmal SVT. The increase in frequency of arrhythmias and in symptoms during pregnancy may be a result of the associated hemodynamic, hormonal, autonomic, and emotional changes. An expanded circulating volume may increase myocardial irritability, and a faster sinus heart rate may alter tissue excitability, initiating a reentry circuit. It has been postulated that estrogens may heighten cardiac excitability as they have this effect on the uterine muscle. Furthermore, estrogens sensitize the myocardium to catecholamines by increasing the number of $\alpha$-adrenergic receptors. ${ }^{16}$

Chang et $\mathrm{al}^{17}$ evaluated the burden of paroxysmal SVT in pregnancy, using a national Taiwanese insurance database of 
Table 3 Cohort studies of the future risk of CVD following MPS, low-birth-weight infant, and/or preterm delivery

\begin{tabular}{|c|c|c|c|c|c|}
\hline Reference & Study design & $\begin{array}{l}\text { Median } \\
\text { follow-up } \\
\text { (y) }\end{array}$ & MPS at baseline & $\begin{array}{l}\text { Future } \\
\text { cardiovascular } \\
\text { event }\end{array}$ & $\begin{array}{l}\text { Adjusted RR }(95 \% \mathrm{CI}) \\
\text { of future event in } \\
\text { the presence of MPS }\end{array}$ \\
\hline \multirow[t]{2}{*}{$\begin{array}{l}\text { Smith et al } \\
(2001)\end{array}$} & \multirow[t]{2}{*}{$\begin{array}{l}\text { Retrospective } \\
\text { cohort }\end{array}$} & \multirow[t]{2}{*}{$15-19$} & Pre-eclampsia & $\begin{array}{l}\text { Ischemic heart } \\
\text { disease }\end{array}$ & $2.0(1.5-2.5)$ \\
\hline & & & $\begin{array}{l}\text { Pre-eclampsia }+ \text { small-for-gesta- } \\
\text { tional age birth weight }+ \text { preterm } \\
\text { delivery before } 37 \mathrm{wk}\end{array}$ & $\begin{array}{l}\text { Ischemic heart } \\
\text { disease }\end{array}$ & $7.0(3.3-14.5)$ \\
\hline \multirow[t]{3}{*}{ Pell et al (2004) } & \multirow{3}{*}{$\begin{array}{l}\text { Retrospective } \\
\text { cohort }\end{array}$} & \multirow[t]{3}{*}{$15-19$} & Low infant birth weight & Major stroke & $1.3(1.0-1.6)$ \\
\hline & & & Preterm delivery before $37 \mathrm{wk}$ & Major stroke & $1.9(1.4-2.7)$ \\
\hline & & & $\begin{array}{l}\text { Low infant birth weight }+ \text { preterm } \\
\text { delivery before } 37 \mathrm{wk}\end{array}$ & Major stroke & $2.7(1.4-5.1)$ \\
\hline \multirow[t]{2}{*}{$\begin{array}{l}\text { Irgens et al } \\
(2001)\end{array}$} & \multirow[t]{2}{*}{$\begin{array}{l}\text { Retrospective } \\
\text { cohort }\end{array}$} & \multirow[t]{2}{*}{13} & Pre-eclampsia & $\begin{array}{l}\text { Cardiovascular } \\
\text { death }\end{array}$ & $1.6(1.0-2.7)$ \\
\hline & & & $\begin{array}{l}\text { Pre-eclampsia }+ \text { preterm delivery } \\
\text { before } 37 \mathrm{wk}\end{array}$ & $\begin{array}{l}\text { Cardiovascular } \\
\text { death }\end{array}$ & $8.1(4.3-15.3)$ \\
\hline $\begin{array}{l}\text { Wilson et al } \\
(2003)\end{array}$ & $\begin{array}{l}\text { Retrospective } \\
\text { cohort }\end{array}$ & $15-19$ & Pre-eclampsia & $\begin{array}{l}\text { Cerebrovascular } \\
\text { disease }\end{array}$ & $2.1(1.0-4.3)$ \\
\hline \multirow[t]{2}{*}{$\begin{array}{l}\text { Kestenbaum et al } \\
(2003)\end{array}$} & \multirow[t]{2}{*}{$\begin{array}{l}\text { Retrospective } \\
\text { cohort }\end{array}$} & \multirow[t]{2}{*}{7.8} & Mild pre-eclampsia & $\begin{array}{l}\text { Cerebrovascular } \\
\text { disease }\end{array}$ & $2.2(1.3-3.6)$ \\
\hline & & & Severe pre-eclampsia & $\begin{array}{l}\text { Cerebrovascular } \\
\text { disease }\end{array}$ & $3.3(1.7-6.5)$ \\
\hline \multirow[t]{3}{*}{ Ray et al (2005) } & \multirow{3}{*}{$\begin{array}{l}\text { Retrospective } \\
\text { cohort }\end{array}$} & \multirow[t]{3}{*}{8.7} & MPS composite & Premature CVD & $2.1(1.8-2.4$ \\
\hline & & & $\begin{array}{l}\text { MPS composite + poor fetal } \\
\text { growth }\end{array}$ & Premature CVD & $3.1(2.2-4.5)$ \\
\hline & & & $\begin{array}{l}\text { MPS composite }+ \text { intrauterine } \\
\text { fetal death }\end{array}$ & Premature CVD & $4.4(2.4-7.9)$ \\
\hline
\end{tabular}

Abbreviations: $\mathrm{Cl}$, confidence interval; CVD, cardiovascular disease; MPS, maternal placental syndrome; RR, relative risk.

Adapted from: Ray JG. Metabolic syndrome and higher risk of maternal placental syndromes and cardiovascular disease. Drug Dev Res 2006;67:607-611.

2.3 million women. Approximately $0.3 \%$ of the women in the study developed SVT. The women who developed SVT during pregnancy were more likely to have adverse maternal and fetal outcomes, including severe maternal morbidity, cesarean section, low birth weight, preterm labor, fetal stress, and obvious fetal abnormalities. In a secondary analysis, Chang et al demon-

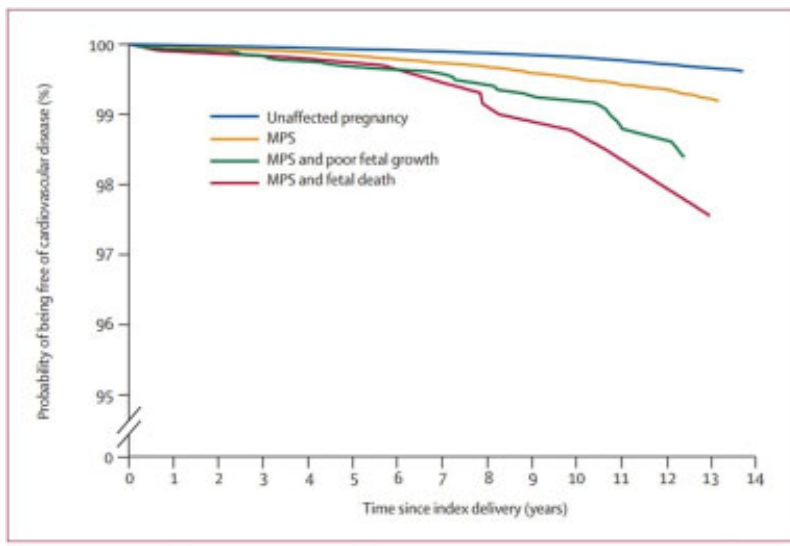

Fig. 3 Increasing risk of premature CVD associated with an MPS or an affected fetus or both. CVD, cardiovascular disease; MPS, maternal placental syndrome. (Adapted from: Ray et $\mathrm{al}^{15}$ ) strated that women with a history of ablation were less likely to have recurrent SVT during pregnancy compared with those with a history of paroxysmal SVT without ablation; however, surprisingly, the adverse event rates were not different between women with and without history of ablation therapy. This finding raises the possibility that a woman's underlying predisposition to SVT may be responsible for the adverse maternal and fetal outcomes rather than the presence of SVT per se.

In a separate report, Vaidya et al ${ }^{18}$ used data from the US Nationwide Inpatient Sample to identify temporal trends in arrhythmias in 57 million pregnancies from 2000 to 2012 . During this period, the authors reported an increase in pregnancy-related hospitalizations with arrhythmias. The rise was due largely to an increased burden of atrial fibrillation and ventricular tachycardia, whereas hospitalizations for SVT remained stable over time. Higher maternal age was reported as evidenced by the substantial increase in arrhythmias in women 41 to 50 years of age. Racial disparities were also reported, with an increased frequency of any arrhythmia in pregnancy among black women compared with other racial groups. The increased frequency of maternal in-hospital death and maternal and fetal complications among women with arrhythmias in pregnancy suggested that these were not entirely benign events ( $\mathbf{- F i g . 4}$ ). 

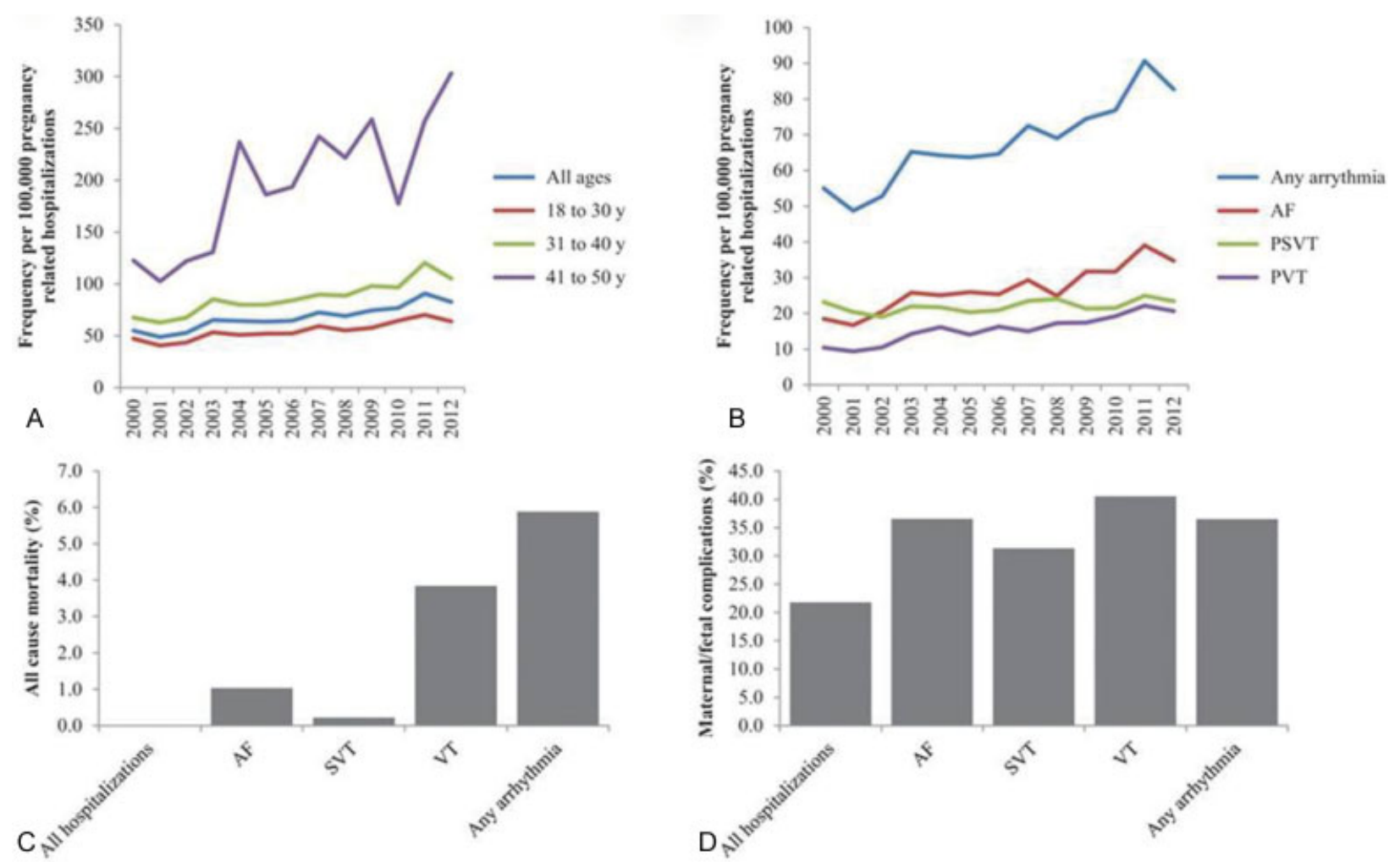

Fig. 4 Frequency of arrhythmias in pregnancy and associated mortality and complications. (A) Pregnancies in females between ages of 41 to 50 years were found to have increased number of arrhythmias. (B) Idiopathic arrhythmias were commonly found in most of the pregnancies followed by AF. (C) Maximum mortality was seen in patients of idiopathic arrhythmias. (D) Maternal and fetal complications were more in patients of AF and VT. AF, atrial fibrillation; PSVT, paroxysmal supraventricular tachycardia; PVT, polymorphous ventricular tachycardia; SVT, supraventricular tachycardia; ventricular tachycardia (VT). (Adapted from: Vaidya et $a^{18}$ )

Whether pregnancy suppresses or exacerbates arrhythmias is unknown. First occurrence of SVT has not been shown to be higher during pregnancy. ${ }^{19}$ Longitudinal studies are needed that relate arrhythmia in pregnancy with future cardiovascular events in women. These studies will help us understand whether having an arrhythmia in pregnancy serves as a noninvasive electrophysiology study or electrophysiology stress test and would allow us to predict whether a woman will have an arrhythmia or CVD later in her life. In addition to risk prediction, future translational and bench studies have the potential to help us uncover biological mechanisms that predispose to arrhythmia development among pregnant women. This would be of importance in lethal electric syndromes such as long-QT and Brugada's syndromes for which counseling about pregnancy and peripartum risk may be important.

\section{Preterm Delivery and Maternal CVD in Young and Middle-Aged Adult Women}

Whereas pregnancy complications such as pre-eclampsia, gestational hypertension, and GDM are more widely known to be related to later cardiometabolic disease in women, the association between preterm delivery and CVD in women is less well appreciated by both clinicians and researchers. The association between preterm delivery and both fatal and nonfatal CVD has been previously demonstrated, with the risk of CVD with preterm delivery being even more pronounced among women delivering a small-for-gestationalage baby.

In a study, Tanz et $\mathrm{al}^{4}$ characterized the risk of cardiovascular events (myocardial infarction and stroke) in women who experienced a preterm delivery. Using data from approximately 70,000 participants in the Nurses' Health Study II, the investigators demonstrated that preterm delivery ( $<37$ weeks' gestation) was associated with future CVD (hazard ratio [HR] of 1.42). Further dividing preterm delivery into moderate preterm $(<37$ weeks and $\geq 32$ weeks) and very preterm ( $<32$ weeks), they demonstrated the highest risk in those with very preterm delivery. The longitudinal nature of the study allowed the authors to adjust for multiple preexisting CVD risk factors and to determine how much of the risk was attributable to the subsequent development of traditional risk factors (e.g., hypertension, diabetes mellitus). Surprisingly, adjusting for preexisting risk factors only modestly attenuated the association, and $<15 \%$ of the associated risk could be attributed to the development of traditional risk factors.

Tanz and coworkers provided more detailed accounting of prepregnancy and subsequent CVD risk factors. This study both confirmed the association between preterm delivery and CVD and suggested that the association is mediated through alternative pathways other than the traditional CVD risk factors. 


\section{Assisted Reproductive Technology}

A growing number of women are considering pregnancy with the help of assisted reproductive technology (ART). Changes in the hormonal environment seen in ART patients initially entail an increase then a decrease in blood pressure and peripheral vascular resistance. A shift in the thrombotic-thrombolytic balance toward coagulation is observed. Moreover, ART-conceived pregnancies exhibit an increased adverse event rate for both the mother and fetus, including a higher incidence of hypertensive disorders and an increase in thrombo-embolic events during the first trimester. Ovarian hyperstimulation syndrome in particular can cause dramatic hemodynamic changes and an increase in upper body thrombosis. Hence, treatment for infertility could predispose a woman for future CVD. ${ }^{20}$

\section{Future Approach-Go Red}

The American Heart Association's Go Red for Women was launched in 2004 to develop a strategic and integrated approach to the care and future research as regards with heart disease in women. ${ }^{21}$

As a part of this campaign, a study conducted at MageeWomen's Research Institute and Foundation in Pittsburgh showed that pregnancy is a complex stressor for women and that complications such as preeclampsia have been associated with increased future CVD risk. Abnormal placental and maternal microvascular responses to pregnancy may unmask vascular risk and provide early insights into pathways for the development of CVD. The center aimed to document that vascular pathology in the placenta can identify women at high risk of CVD, 1 and 10 years postpregnancy. They also would assess whether erosion of glycocalyx, a protective coating on vascular endothelial cells, is a mechanism of microvascular dysfunction linking pregnancy complications and future CVD risk. Examination of mouse models to determine whether pregnancy directly affects CVD and whether the nutrient L-citrulline can be used as a potential therapy to restore the glycocalyx and reduce the progression of atherosclerosis would also be an integral component of research in this center. This research might generate insight into common mechanisms for vascular and placental pathology and how pregnancy-related signals might be used to identify women at increased CVD risk later in life.

\section{Conclusion}

The growing body of evidence suggests that it is no longer a matter of debate that pregnancy-related events are a harbinger of CVD. The present review suggests that besides the common risk factors such as gestational hypertension, gestational diabetes, and preeclampsia, preterm delivery, ART-related pregnancy events, and arrhythmias also have a bearing on future cardiovascular risk among women.

Hence, as community health workers, gynecologists, physicians, and cardiologists, we should utilize the opportunity of pregnancy as stress test for timely prevention in women at risk. Moreover, the future in this field is bright as several novel biomarkers of therapeutic interest study association between pregnancy and future cardiovascular risk.

\section{References}

1 Warnes CA. Pregnancy and Heart Disease. In: Braunwald's Heart Disease. 9th ed. Philadelphia, PA: Saunders; 1770-1780

2 Uzan J, Carbonnel M, Piconne O, Asmar R, Ayoubi J-M. Preeclampsia: pathophysiology, diagnosis, and management. Vasc Health Risk Manag 2011;7:467-474

3 Bellamy L, Casas JP, Hingorani AD, Williams DJ. Pre-eclampsia and risk of cardiovascular disease and cancer in later life: systematic review and meta-analysis. BMJ 2007;335(7627):974

4 Tanz LJ, Stuart JJ, Williams PL, et al. Preterm delivery and maternal cardiovascular disease in young and middle-aged adult women. Circulation 2017;135(06):578-589

5 Irgens HU, Reisaeter L, Irgens LM, Lie RT. Long term mortality of mothers and fathers after pre-eclampsia: population based cohort study. BMJ 2001;323(7323):1213-1217

6 Oakley C. In: Tawam M, Levine J, Mendelson M, Goldberger J, Dyer A, Kadish A, et al, eds. Heart Disease in Pregnancy. 1st ed. London, UK: British Medical Association; 1997:248 \pm 93

7 Funai EF, Friedlander Y, Paltiel O, et al. Long-term mortality after preeclampsia. Epidemiology 2005;16(02):206-215

8 Lykke JA, Langhoff-Roos J, Sibai BM, Funai EF, Triche EW, Paidas MJ. Hypertensive pregnancy disorders and subsequent cardiovascular morbidity and type 2 diabetes mellitus in the mother. Hypertension 2009;53(06):944-951

9 Burlina S, Dalfrà MG, Chilelli NC, Lapolla A. Gestational diabetes mellitus and future cardiovascular risk: an update. Int J Endocrinol 2016;2016:2070926

10 Retnakaran R, Shah BR. Mild glucose intolerance in pregnancy and risk of cardiovascular disease: a population-based cohort study. CMAJ 2009;181(6-7):371-376

11 O'Brien TE, Ray JG, Chan WS. Maternal body mass index and the risk of preeclampsia: a systematic overview. Epidemiology 2003; 14(03):368-374

12 Innes KE, Wimsatt JH, McDuffie R. Relative glucose tolerance and subsequent development of hypertension in pregnancy. Obstet Gynecol 2001;97(06):905-910

13 Ray JG, Diamond P, Singh G, Bell CM. Brief overview of maternal triglycerides as a risk factor for pre-eclampsia. BJOG 2006;113 (04):379-386

14 Roberts JM. Endothelial dysfunction in preeclampsia. Semin Reprod Endocrinol 1998;16(01):5-15

15 Ray JG, Vermeulen MJ, Schull MJ, Redelmeier DA. Cardiovascular health after maternal placental syndromes (CHAMPS): populationbased retrospective cohort study. Lancet 2005;366(9499):1797-1803

16 Roberts JM, Insel PA, Goldfien A. Regulation of myometrial adrenoreceptors and adrenergic response by sex steroids. Mol Pharmacol 1981;20(01):52-58

17 Chang SH, Kuo CF, Chou IJ, et al. Outcomes associated with paroxysmal supraventricular tachycardia during pregnancy. Circulation 2017;135(06):616-618

18 Vaidya VR, Arora S, Patel N, et al. Burden of Arrhythmia in Pregnancy. Circulation 2017;135(06):619-621

19 Sanghavi M, Parikh NI. Harnessing the power of pregnancy and pregnancy-related events to predict cardiovascular disease in women. Circulation 2017;135(06):590-592

20 Rossberg N, Stangl K, Stangl V. Pregnancy and cardiovascular risk: a review focused on women with heart disease undergoing fertility treatment. Eur J Prev Cardiol 2016;23(18):1953-1961

21 Mosca L, Ouyang P, Hubel CA, Reynolds HR, Allison MA. Go Red for Women Strategically Focused Research Network Centers. Circulation 2017;135(06):609-611 